\title{
Suatu Kajian Literatur Aplikasi Radio Frequency Identification dalam Bidang Pertanian
}

\author{
Wenny Marthiana ${ }^{1^{*}}$, Nizwardi Jalinus ${ }^{2}$ \\ ${ }^{1}$ Jurusan Teknik Mesin, Fakultas Teknologi Industri, Universitas Bung Hatta Padang \\ ${ }^{2}$ Jurusan Teknik Mesin, Fakultas Teknik, Universitas Negeri Padang \\ *Corresponding author, e-mail: wenny_ma@yahoo.com
}

\begin{abstract}
Abstrak- Salah satu jenis system informasi yang saat ini mengalami perkembangan pesat adalah RFID (Radio Frequency Identification). Sistem tersebut digunakan memiki fleksibilitas yang tinggi, mudah digunakan, serta sangat sesuai pada aktivitas yang memerlukan otomatisasi. Sisem ini juga telah digunakan untuk menggantikan fungsi sistem Barcode yang dianggap kurang fleksibel terutama dalam hal tracerability. Tulisan ini bertujuan untuk menggali potensi penerapan RFID dalam bidang pertanian, baik dalam perkembangan teknologi, aplikasi apa saja yang dapat digunakan dengan RFID, kendala serta Prospeknya. Hal tersebut guna membantu dalam mengarahkan sector pertanian sesuai dengan revolusi 4.0, agar pertanian di daerah kecil utamanya, mampu bersaing di globalisasi. Adapun metoda yang digunakan adalah dengan review terhadap Jurnal penelitian sehubungan dengan RFID, dan aplikasinya di Dunia Pertanian. Dari 100 Jurnal yang diunduh, hanya sekitar 53 Jurnal yang sejalan dengan tujuan review ini. Adapun sumber JUrnal adalah. Google Scholar, World Web of Science (WWS), Science Direct dan jurnal open access lainnya. Adapun sebagian besar penelitian diperoleh melalui metode pencarian
\end{abstract}

Kata kunci: Teknologi RFID, Aplikasi RFID, masalah RFID, RFID di bidang pertanian, Teknologi RFID.

Abstract-One type of information system that is currently experiencing rapid development is RFID (Radio Frequency Identification). The system is used to provide high flexibility, easy to use, and is highly suited to activities that require automation. This system has also been used to replace the Barcode system function which is considered less flexible especially in the case of tracerability. This paper aims to explore the potential application of RFID in agriculture, both in technological developments, what applications can be used with RFID, constraints and Prospects. This is to assist in directing the agricultural sector in accordance with revolution 4.0 , in order for agriculture in the small area primarily, able to compete in globalization. The method used is a review of the research journal in connection with RFID, and its application in the World of Agriculture. Of the 100 Journals downloaded, only about 53 Journals are in line with the purpose of this review. The source of JUrnal is. Google Scholar, World Web Science (WWS), Science Direct and other open access journals. The majority of research is obtained through the search method

Keywords: RFID Technology, RFID Application, RFID problem, RFID in agriculture, RFID Technology.

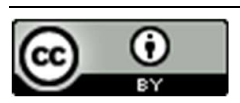

This is an open access article distributed under the Creative Commons 4.0 Attribution License, which permits unrestricted use, distribution, and reproduction in any medium, provided the original work is properly cited. (C2018 by Author and Universitas Negeri Padang

\section{Pendahuluan}

Teknogi Informasi yang perkembangannya kini tak dapat lagi terbendung akan banyak memberikan manfaat bagi perusahaan, perorangan maupun isntritusi yang mampu memanfaatkannya. Penggunaan Sistem informasi yang juga telah memasuki seluruh bidang yang dimanfaatkan dengan tepat dapat meningkatkan performansi, seperti produktiviats, efisinsi pada hampir di setiap aktivitas kegiatannya.

Perkembangan system informasi telah mengarah kepada keakuratan penggunaannya serta aplikasi realntime, dimana hal tersebut menjadi bagian persyaratan utama dalam aplikasi suatu sistem informasi dan menjadi andalam utama para 
penggunanya.

Smart farming (SF), berdasarkan penggabungan teknologi informasi dan komunikasi ke dalam mesin, peralatan, dan sensor dalam sistem produksi pertanian, memungkinkan volume besar data dan informasi yang dihasilkan denganpenyisipan otomatisasi progresif ke dalam proses. Pertanian cerdas bergantung pada transmisi data dan konsentrasi data dalam sistem penyimpanan jarak jauh untuk memungkinkan kombinasi dan analisis berbagai data pertanian untuk pengambilan keputusan [1]

Kecenderungan demografis, termasuk populasi yang menua dan migrasi penduduk terus-menerus dari daerah pedesaan ke perkotaan, telah menarik perhatian para peneliti, karena masalah tenaga kerja dapat menjadi faktor kelangkaan di bidang pertanian. Selain tren ini, intensifikasi perubahan iklim akan terus mengubah kondisi pertumbuhan, seperti suhu, curah hujan, dan kelembaban tanah, dengan cara yang kurang dapat diprediksi [2].

Peralatan yang digunakan dalam smart Farming, antara lain dapat membantu mengurangi dampak migrasi penduduk pedesaan ke perkotaan serta semakin menuanya populasi penduduk, menjaga mereka konstan atau mengurangi biaya produksi dalam kegiatan pertanian, dan mereka dapat membantu dalam meminimalkan kendala lingkungan [3].

Literatur tentang pertanian cerdas dan pertanian cerdas baru-baru ini. Konsep dan istilah yang terkait dengan SF belum mencapai konsensus dalam literatur ilmiah [4].

Perkembangan yang cepat di internet of things (IoT) dan cloud computing mendorong fenomena yang disebut pertanian pintar [5]. Dasar untuk kemajuan di sektor ini melibatkan kombinasi teknologi internet dan teknologi yang berorientasi masa depan untuk digunakan sebagai objek pintar [6-9];

SF adalah konsep yang berasal dari rekayasa perangkat lunak dan ilmu komputer [10] yang diperoleh dengan penambahan teknologi komputasi dan transmisi data dari pertanian, dalam lingkungan keseluruhan komputasi virtual [4]. Unsur-unsur komputasi ini tertanam dalam objek dan saling berhubungan satu sama lain dengan internet.

SF dan Smart Agriculture merupakan suatu istilah yang memiliki arti yang sama, nampaknya mengalami tumpang tindih interface dan teknology terhadap ide-ide pertanian presisi serta yang berasal dari ide sistem informasi manajemen pertanian (FMIS) [10]. FMIS didefinisikan sebagai sistem yang dirancang untuk mengumpulkan, memproses, menyimpan, dan menyebarluaskan data dalam format yang diperlukan untuk melakukan operasi dan fungsi pada properti pedesaan [11].

Aplikasi SF dimungkinkan karena penggunaan sensor di bidang pertanian. Sensor adalah perangkat elektroteknik yang mengukur kuantitas fisik dari lingkungan dan mengubah pengukuran ini menjadi sinyal yang dapat dibaca oleh instrumen. Variabel pengukuran yang dibaca oleh sensor antara lain seperti: suhu, kelembaban, cahaya, tekanan, tingkat kebisingan, ada atau tidak adanya jenis objek tertentu, tingkat stres mekanik, kecepatan, arah, dan ukuran suatu objek [12][21][22]

Internet of things (IoT), yang merupakan salah satu teknologi yang terkait dengan SF, awal diperkenalkan oleh seorang pengusaha dari inggris bernama Kevin Ashton, pada tahun 1999, yang juga berbagi konsep lingkungan yang cerdas dengan FMIS[13]. IOT memungkinkan objek untuk dikendalikan dari jarak jauh melalui infrastruktur jaringan yang ada, sehingga menciptakan peluang untuk integrasi langsung antara dunia fisik dansistem berbasis komputer. [32]

Penggunaan IoT sangat tergantung pada infrastruktur internet, hal ini memiliki beberapa kekurangan, terutama ketika berhadapan dengan sejumlah besar perangkat jaringan dan integrasi dengan sistem lain[14]. SF memperkenalkan tingkat teknologi baru ke dalam pertanian, termasuk teknologi robotika, pemetaan dan geomatika, pengambilan keputusan dan proses statistik.[32][46]

Teknologi SF yang paling menjanjikan telah memasukkan kemajuan dalam sensor, analisis data, telemetri, dan teknologi penentuan posisi, namun pengembangan dan diseminasi teknologi ini mungkin memerlukan waktu yang cukup lama dan investasi yang tidak kecil.

Perkembangan informasi dan Teknologi (Information Computer and technology, ICT) memperlihatkan adanya dua peluang berbeda untuk menerapkan model ICT modern untuk pemodelan dalam sistem pertanian. Pertama, adanyakemajuan seperti data dan sumber data yang sangat besar, penginderaan jarak jauh, dan komputasi kinerja tinggi dapat digunakan untuk memajukan ilmu smageling sistem pertanian. Kedua, teknologi baru dapat digunakan untuk mengubah praktik dan penerapan pemodelan sistem pertanian dengan membuatnya jauh lebih kolaboratif, terdistribusi, fleksibel, dan mudah diakses[15] 
Perkembangan yang sedang berlangsung di ICT menawarkan potensi yang signifikan untuk mengelola informasi di tingkat petani. Teknologi penginderaan, setidaknya pada prinsipnya, menawarkan kepada para petani kemampuan untuk memantau pertanian mereka dengan tingkat detail yang belum pernah terjadi sebelumnya, dalam berbagai dimensi dan mendekati waktu nyata. Hal ini menawarkan kemungkinan yang menarik untuk mengembangkan model spesifik pertanian yang dapat digunakan oleh petani individu untuk merencanakan kegiatan mereka dalam menanggapi perubahan keadaan, sehingga memungkinkan eksplorasi berbagai trade-off yang melekat dalam proses pengambilan keputusan sembari mengelola masalah informasi yang berlebihan [16][20]

Sistem identifikasi barang, hewan dan orang terus berkembang, juga sebagai hasil dari penelitian teknologi yang memperkenalkan dan secara bertahap meningkatkan solusi yang mampu membawa keuntungan yang tidak diragukan pada perencanaan operasi baik untuk perusahaan maupun pribadi yang menggunakannya. Teknologi informasi terkini dan perkembangan paralel sistem organisasi baru memungkinkan perusahaan untuk mengelola data yang terkait dengan proses produksi secara lebih efisien dan efektif dan untuk mengembangkan komunikasi yang benar baik di dalam maupun di luar perusahaan [17][48]

Dengan mengacu pada masalah keamanan data, pelacakan dan identifikasi objek secara otomatis, dalam beberapa tahun terakhir, minat khusus sedang ditentukan oleh apa yang disebut "RFId" (Identifikasi Frekuensi Radio), yaitu suatu akronim yang digunakan untuk menunjukkan semua aplikasi yang menggunakan frekuensi radio untuk mengidentifikasi-mengenali-menemukan suatu objek. [17-18]

Secara sederhana, sistem ini didasarkan pada pembacaan jarak jauh informasi yang terkandung dalam suatu label tertentu (tag RFId), yang diaktifkan oleh pembaca khusus (Rader); Dengan cara ini, melalui pulsa elektromagnetik, menjadi mungkin untuk mengkodifikasikan data yang terdapat dalam tag yang menyertai produk selama seluruh proses produksi [1]

Pertimbangan lain yang menjafikan RFID saat ini mengalami perkembangan pesat adalah karena Sistem tersebutmemiki fleksibilitas yang tinggi, mudah digunakan, serta sangat sesuai pada aktivitas yang memerlukan otomatisasi. Sisem ini juga telah digunakan untuk menggantikan fungsi sistem Barcode yang dianggap kurang fleksibel terutama dalam hal tracerability.

Dalam analisa ini ingin direview bagai mana aplikasi RFID dalam smart Farming khususnya dalam memonitor kondisi kelembaban tanah.

\section{StUdi PUSTAKa}

\section{A. Teknologi RFID}

RFID adalah istilah yang diciptakan untuk teknologi radio jarak pendek yang digunakan untuk berkomunikasi terutama informasi digital antara lokasi stasioner dan objek bergerak atau antara benda bergerak. Berbagai frekuensi radio dan teknik digunakan dalam sistem RFID. Salah satu ujung menggunakan perangkat sederhana (sisebut Tag atau transponder), tag dapat digunakan dalam jumlah sangat besar, melekat pada objek yang akan dikelola, dan beroperasi secara otomatis.

Tag biasanya dibangun menggunakan sirkuit CMOS atau gelombang akustik permukaan (SAW) perangkat atau resonator dapat diaktifkan oleh baterai atau dengan perbaikan sinyal radio yang dikirim oleh pembaca, dapat mengirim data ke pembaca dengan mengubah pemuatan antena tag dengan cara yang dikodekan atau dengan menghasilkan, memodulasi, dan mentransmisikan sinyal radio.

Sedang ujung lainnya, dapa dinamai sebagai : pembaca, redear, interrogator atau, suar, terhubung ke komputer atau jaringan induk, dengan Frekuensi radio yang dapat digunakan dari 100 kHz hingga $10 \mathrm{GHz}$. [19][33]

Teknologi RFID muncul ketika Frederick Hertz menemukan adanya frekuensi radio selama eksperimennya pada tahun 1886 (Wyld, 2005) dan dikembangkan untuk tujuan pertahanan selama Perang Dunia Kedua4. Selama 1970-an dan 1980an, sistem RFID menarik banyak sarjana dan inovator, sehingga upaya untuk mendaftarkan paten berkembang (Takahashi, 2004). Peneliti seperti Charles Walton telah mendaftarkan paten untuk menggunakan RFID. Pada 1980-an, banyak perusahaan AS dan Eropa mengakui pentingnya mengembangkan teknologi RFID dan mulai memproduksi tag RFID. Segera para sarjana di MIT University membuka pusat Auto-ID untuk mempromosikan penggunaan dan implementasi teknologi RFID. Tetapi sebagian besar ulama melaporkan bahwa komersialisasi teknologi RFID pertama dilakukan oleh Wal-Mart ketika mereka meluncurkan sistem identifikasi materi berbasis RFID pada tahun 2005 (Shahram dan

Manish 2005). Wal-Mart kini melacak barang dagangan termasuk makanan, pakaian, dan barang elektronik dengan teknologi RFID dalam rantai 
pasokan mereka. Teknologi RFID adalah alat kebijakan baru yang dapat memastikan transparansi, efisiensi dan keefektifan yang tinggi tidak hanya di bidang industri tetapi juga dalam penyediaan layanan pemerintah. [24]

\section{B. Komponen Utama}

RFID memiliki 3 komponen Utama, yaitu (1) RFID tag (2) Reader (3) Processor/Controler. Sebuah tag RFID terdiri dari microchip silikon yang melekat pada antena kecil dan dipasang pada substrat dan dikemas dalam bahan yang berbeda seperti kerudung plastik atau kaca dan dengan perekat di sisi belakang untuk ditempelkan ke objek.

Reader Ini terdiri dari pemindai dengan antena untuk mengirim dan menerima sinyal dan bertanggung jawab untuk komunikasi dengan tag dan menerima informasi dari tag. Prosesor atau Pengontrol: Ini dapat berupa komputer induk dengan Mikroprosesor atau mikrokontroler yang menerima input pembaca dan memproses data $[5][19][23]$

\section{Keterbatasan RFID}

1. Standarisasi: Meskipun karakteristik aplikasi dan lingkungan penggunaan menentukan tag yang tepat, standar yang jarang masih meninggalkan banyak kebebasan dalam pilihan protokol komunikasi dan format dan jumlah informasi yang disimpan dalam tag

2. Biaya: Biaya tag tergantung pada tipenya.

3. Collision: Mencoba membaca beberapa tag sekaligus dapat mengakibatkan tabrakan sinyal dan akhirnya kehilangan data. Untuk mencegah hal ini, algoritma anti-tabrakan (kebanyakan dipatenkan atau dipatenkan paten) dapat diterapkan dengan biaya tambahan. Pengembangan metode ini, yang bertujuan untuk mengurangi waktu baca secara keseluruhan dan memaksimalkan jumlah tag yang dibaca secara bersamaan, tetap berjalan.

4. Frekuensi: Pilihan frekuensi yang optimal bergantung pada mode Transmisi, tag perilaku, dan Wilayah standar internasional dalam alokasi frekuensi Karena alasan historis, dunia dibagi menjadi tiga wilayah besar alokasi frekuensi untuk berbagai tujuan, wilayah (1) yang mengandung Eropa, Afrika, Timur
Tengah dan negara-negara anggota SU sebelumnya, wilayah. (2) dengan Amerika Utara dan Selatan dan bagian dari Pasifik timur dari garis tanggal, dan wilayah (3) dengan Asia, Australia dan Pasifik barat dari garis tanggal

5. Pembuatan label yang salah: Pembuatan tag belum $100 \%$ bebas dari kegagalan hari ini; sekitar $20-30 \%$ dari tag yang digunakan pada awal RFID pilot telah rusak.

6. Pendeteksian tag yang salah atau kurang

7. Cepatnya Kemunduran teknologi: Salah satu keprihatinan umum perusahaan yang menerapkan RFID saat ini adalah keusangan teknologi yang cepat, terutama mengingat biaya investasi. Teknologi terus berkembang dan standar protokol yang baru.

8. Masalah Keamanan dan Privasi [17],[19],[24], [25][33]

\section{RFID dalam Pertanian}

RFID dapat melakukan kontrol otomatis untuk banyak hal. Sektor manufaktur, retail, perpustakaan, logistik, supply chain dan medis telah banyak mengaplikasikan teknologi sistem informasi ini.

Beberapa rumah sakit di dunia telah berhasil mengimplementasikan teknologi RFID pada area penelusuran pasien, staf medis, peralatan medis dan area aplikasi lainnya.

Sistem-sistem RFID menawarkan peningkatan efisiensi dalam pengendalian inventaris (inventory control), logistik dan manajemen rantai supply (supply chain management). RFID juga dapat digunakan oleh peritel sebagai teknologi peralatan lacak (tracking) dan label pintar yang ditanamkan pada sensor-sensor pentransmisi dan reader cerdas untuk mentransmisikan informasi tentang areaarea kunci di mana konsumen tinggal dan bekerja untuk sistem pemrosesan data.

Dalam dunia pertanian aplikasi RFID antara lain digunakan untuk keperluan (1) pemantauan kondisi kelembaban tanah serta komposisi tanah, (2) pengaturan kebutuhan air atau sistem irigasi, (3) Pemantauan Temperatur, (4) Tracking pengiriman hasil pertanian, (5) Pemantauan Lahan Pertanian, (6) Monitoring alat pertanian maupun pergerakan alat bantu pertanian, (7) Pemantauan Penyakit maupun serangan hama, (8) pemantauan Cuaca [28-52] 


\section{METODE}

Tinjauan dilakukan dengan mencari data berbasis online untuk mengidentifikasi publikasi RFID antara tahun 2005 dan 2018. Tinjauan dilakukan dengan mengkategorikan aplikasi RFID dan menganalisis masalah yang dihadapi oleh RFID saat ini dengan meninjau literatur yang dipublikasikan.

Pengumpulan literatur yang digunakan untuk tinjauan sistematis dari sebagian besar studi ditemukan dengan mencari e-database. Akses basis data elektronik yang dilakukan seperti Google Scholar, World Web of Science (WWS), Science Direct dan jurnal open access lainnya. Adapun sebagian besar penelitian diperoleh melalui metode pencarian ini.dengan menggunakan Key word yang digunakan antara lain 'teknologi RFID', 'aplikasi RFID, dan' masalah RFID 'RFID di bidang pertanian', 'teknologi RFID' untuk menelusuri literatur.

Adapun tinjauan sistematis yang dilakukan berdasarkan data literatur penelitian sebelumnya, dilakukan berdasarkan langkah berikut, Pertama, jumlah total studi awal yang kami temukan dari edatabase adalah 100. Kedua, mengecualikan 53 berikut kriteria kelayakan umum dengan menyaring judul dan abstrak. Lebih khusus lagi, kami memasukkan studi RFID hanya dengan kriteria berikut: 1) studi yang berfokus pada pertanian; 2) studi dengan mempertimbangkan menerapkan teknologi RFID; 3) studi tentang dampak RFID dalam kehidupan sosial ; Singkatnya, kami hanya memasukkan 53 makalah yang membahas masalah RFID dan implikasinya di bidang pertanian.

\section{Hasil dan Pembahasan}

Penerapan Internet of Thing pada pertanian dapat digunakan kebutuhan akan bahan makanan di seluruh dunia yang meningkat setiap tahunnya. Internet of Things bukan diterapakan pada rantai pemasok pertanian tetapi juga teknologi sensor untuk penggunaan air, sensor untuk mendeteksi serangan hama, dan juga sensor yang mempertahankan suhu kondisi lingkungan. Dengan penerapan tersebut hasil pertanian dapat meningkat dengan pesat.

Teknologi IOT mengunakan aplikasi yang memproses informasi dan infrastruktur. Aplikasi Internet of Things (IOT) mirip dengan realisasi dari pengetahuan produksi pertanian, manajemen, pengambilan keputusan, yang terkait dengan produksi pertanian. Aplikasi Internet Of Things (IOT) meliputi fasilitas psoes data pertumbuhan tanaman, manajemen digital dari produksi, pembagian data, user Interface dan service intelligent network serta decision-making.[27] [46] [48]

Konsep dari Internet Of Things terkait dengan network, yang mengkoneksikan segala sesuatu dengan internet melalui Radio frequency Identification (RFID), sensor, global positioning systems (GPS), laser scanner dan sensor informasi lainnya menurut protocol yang di setujui dan pertukaran informasi yang mendapatkan idetifikasi pengetahuan, pelacakan lokasi, monitoring dan manajemen.

Jaringan bisa melakukan identifikasi secara otomatis pada objek dan lokasi, jalur, monitor dan memicu koreponden peristiwa. Dengan menggunakan tyeknologi RFID untuk melakukan scanning dan membaca tag EPC pada barang dan mendapatkan informasi idetitas dari barang dan membagikan informasi terkait barang tersebut [34].

\section{a. Macam-Macam Aplikasi}

Dari jurnal yang membahas mengenai RFiD dalam dunia pertanian pemanfaat RFiD digunakan untuk beberapa keperluan seperti Pemantauan cuaca, temperatur, kelembaban tanah, penyakit, gulma, kondisi tanaman lainnya, efisiensin tenaga kerja, optimalisasi alat pertanian, peringatan irigasi, identifikasi tanaman, identifikasi tanah, Nutrisi, Tanggal Panen. Pada produk hasil pertanian digunakan untuk ketelusuran produk, sistem rantai suply.[21-52]

\section{b. Sistem}

Adapun Label yang digunakan dari jenis aktif maupun pasif. Label RFID aktif biasanya lebih besar dan lebih mahal untuk diproduksi karena memerlukan sumber listrik. Label RFID aktif memancarkan sinyalnya ke pembaca label dan biasanya lebih andal dan akurat daripada label RFID pasif. Label RFID aktif memiliki sinyal lebih kuat sehingga dapat digunakan pemakaiannya di lingkungan yang sulit terjangkau seperti di bawah air, atau dari jauh untuk mengirimkan data.Label Pasif RFID tidak memiliki pasokan listrik internal dan bergantung pada pembaca RFID untuk mengirimkan data. Sebuah arus listrik kecil diterima melalui gelombang radio oleh antena RFID dan daya CMOS [33] hanya cukup untuk mengirimkan tanggapan. Label Pasif RFID lebih 
cocok untuk lingkungan pergudangan di mana tidak ada banyak gangguan dan jarak yang relatif pendek (biasanya berkisar dari beberapa inci sampai beberapa meter). Karena tidak ada sumber daya internal, label pasif RFID lebih kecil dan lebih murah untuk diproduksi.

\section{c. Prospek}

Prospek RFID di masa depan di bidang pertanian sangat terbuka, berapa bagian antara lain pada (a) teknologi sensor pertanian; (b) teknologi transmisi nirkabel; (c) teknologi RFID; (d) teknologi keamanan kualitas produk pertanian; (e) teknologi irigasi cerdas; dan (f) teknik penyemaian dan penyemprotan presisi.

RFID menekankan bahwa teknologi RFID dapat menjamin efektivitas danefisiensi dengan harga yang sangat murah. Namun demikian, bukti substansial untuk menunjukkan RFID dapat menghasilkan biaya tak terduga . Pada kenyataannya, tag RFID jauh lebih mahal daripada barcode, yang sangat populer dalam mengidentifikasi bahan sebelum munculnya teknologi RFID. Membeli perangkat, perangkat keras, dan tag RFID tidak cukup untuk mendorong sistem secara relevan. Untuk menjamin kualitas layanan yang lebih baik, sistem RFID membutuhkan lebih banyak hal-hal seperti "mekanisme proses melingkar, kekayaan konsultan, manajer proyek, programer dan tenaga kerja proyek yang berlimpah" Elemen-elemen ini untuk kinerja RFID yang lebih baik mungkin melibatkan biaya yang cukup besar. melaporkan bahwa konsumen teknologi RFID dan pemerintah harus membayar biaya tambahan yang tersembunyi dalam industri perawatan kesehatan [33]. Ketidak efektifan manfaat juga dapat disebabkan minimnya pengetahuan baru, dan kemampuan dari pengguna, dalam hal ini adalah petani, untuk itu perlu dilakukan kegiatan pelatihan dengan strategi yang tepat dalam melaksanakan pelatihan [53] bagi para petani tersebut dan agar pelatihan tidak membosankan serta mudah dipahami, terutama oleh petani yang secara umum tingkat pendidikannya minimum [54] Selanjutnya didukung dengan media dan alat disesuaikan dengan kebutuhan[55]

\section{KESIMPULAN}

Dari temuan berdasarkan tinjauan sistematis dari 53 studi RFID, terdapat enam bidang utama aplikasi RFID. Meskipun manfaat potensial dari aplikasi RFID cukup banyak, berbagai masalah tak terduga juga muncul. RFID masih memiliki kekurangan teknologi, terutama dalam mengamankan teknik kriptografi, standar frekuensi internasional, dan kapasitas penyimpanan. Teknologi RFID tidak cukup efektif dan efektif di beberapa area . Korupsi tag dan pembaca dapat merusak transparansi dan keamanan. Masalah privasi masih merupakan masalah paling serius yang dihadapi oleh RFID saat ini (Naumann dan Hogben 2008). RFID sendiri dapat menghasilkan literasi digital dan distribusi daya yang tidak setara, terutama di negara-negara berkembang. Bahkan teknologi inovatif terbaru, seperti RFID, tidak memiliki jawaban sempurna untuk mengamankan efisiensi, efektivitas, kenyamanan, dan transparansi. Tinjauan

sistematisRFID dalam bidang pertanian ini tidak lengkap untuk membahas semua masalah RFID dari teknologi dikarenakan sumber data yang digunakan sangatlah sedikit untuk dapat mengeneralisasi kondisi aplikasi RFID. Namun dengan adanya penelitian yang sangat banyak mengenai aplikasi RFID khususnya di bidang pertanian banyak membantu untuk mengatasi kekurangan dari RFID

\section{DAftar Pustaka}

[1] Dieisson Pivoto . et al. Scientific development of smart farming technologies and their-application in Brazil. https://doi.org/10.1016/j.inpa.2017.12.002.. 2214-3173 2018 China Agricultural University. Publishing services by Elsevier B.V.

[2] Lisandro Roco. The Impact of Climatic Change Adaptation on Agricultural Productivity in Central Chile: A Stochastic Production Frontier Approach. Sustainability 2017, 9, 1648; doi:10.3390/su9091648. ww.mdpi.com/journal/ sustainability

[3] Fountas S, Carli G, Sørensen CG, Tsiropoulos Z, Cavalaris C, Vatsanidoud A, et al. Farm management information systems: current situation and future perspectives. Comput Electron Agric 2015;115:40-50.

[4] Wolfert S, Ge L, Verdouw C, Bogaardt M. Big data in smart farming: review. Agric Syst 2017;153:69-80

[5] Sundmaeker H, Verdouw C, Wolfert S, Pe'rez Freire L. Internet of food and farm 2020. In: Vermesan O, Friess P, editors. Digitising the industry: internet of things connecting physical, 
digital and virtual worlds. Peter Friess: River Publishers; 2016. p. 129-51.

[6] Brettel M, Friederichsen N, Keller M, Rosenberg M. How virtualization, decentralization and network building change the manufacturing landscape: an industry 4.0 perspective. IJMEA 2014;8(1):37-44.

[7] Lasi H, Fettke P, Kemper HG, Feld T, Hoffmann M. Industry 4.0. Bus Inf Syst Eng 2014;6(4):239-42.

[8] Liao Y, Deschamps F, Loures EDFR, Ramos LFP. Past, present and future of industry $4.0-\mathrm{a}$ systematic literature review and research agenda proposal. Int J Prod Res 2017;55(12): 3609-29.

[9] Maynard AD. Navigating the fourth industrial revolution. Nat Nanotechnoly 2015; 10(12): 1005-6.

[10] Beecham Research. Towards smart farming: agriculture embracing the IoT vision.Link: http://www. beechamresearch.com/files/BRL\% 20Smart\%20Farming_\%_20Executive\%20Sum mary.pdfhttp://www._eechamresearch.com/files /BRL \%20Smart $\% 20$ Farming\%

20Executive\%20Summary.pdf; 2014.

[11] Sørensen CG, Fountas S, Nash E, Pesonen L, Bochtis D, Pedersen SM, et al. Conceptual model of a future farm management information system. Comput Electron Agric 2010;72(1):3747.

[12] Lehmann RJ, Reiche R, Schiefer G. Future internet and the agri-food sector: state-of-the-art in literature and research. Comput Electron Agric 2012;89:158-74.

[13] Gubbi J, Buyya B, Marusic S, Palaniswami M, et al. Internet of Things (IoT): a vision, architectural elements, and future directions. Future Gen Comput Syst 2013;29(7):1645-60.

[14] Kaloxylos A et al. Farm management systems and the future internet era. Comput Electron Agric 2012;89:130-44.

[15] Sander J.C. Janssen a, Towards a new generation of agricultural system data, models and knowledge products: Information and communication technology . Agricultural Systems 155 (2017) 200-212. Elseiver

[16] Michael J. O'grady, G. M. Modelling Thesmart Farm. Information Processing In Agriculture 4 (2017) 179-187

[17] Erica Varese, S. B. Application Of Rfid Technology To The Agroindustrial Sector : Analysis Of Some Case Studyies. J. Commodity Sci. Technol. Quality 2008, 47 (I-Iv), 171-190.

[18] F.D'Ascenzo, "RFId: Feature of technologies and applications in a concrete experimental environment", Journal of Commodity Science, Technology and Quality 2005, Vol. 44 (II-IV), April-December.

[19] Jeremy Landt. History Of Rfid Technology. Journal Ieee Potentials ( Volume: 24, Issue: 4, Oct.-Nov. 2005 )

[20] Aldillah, R. Kinerja Pemanfaatan Mekanisasi Pertanian Dan Implikasinya Dalam Upaya Percepatan Produksi Pangan Di Indonesia. Forum Penelitian Agro Ekonomi, Vol. 34 No. 2, Desember 2016: 163-177.

[21] Athanasios T. Balafoutis, B. B.-E.-B. . Smart Farming Technologies - Description, Taxonomy And Economic Impact.

[22] B D Dokin, A. A. Prospects And Features Of Robotics In Russian Crop Farming. IOP Conf. Series: Journal of Physics: Conf. Series 803 (2017) $012032 \quad$ doi:10.1088/17426596/803/1/012032.

[23] Hongsheng Xu, R. Z. Using RFID technology to development of agricultural products quality safety traceability system on Internet of things. Journal of Chemical and Pharmaceutical Research, 2014, 6(10):632-638

[24] Lee, K. J. A systematic review of RFID applications and diffusion: key areas and public policy issues. Journal of Open Innovation: Technology, Market, and Complexity (2015) 1:9 DOI 10.1186/s40852-015-0010-z .

[25] Luis Ruiz-Garcia, L. L. The role of RFID in agriculture: Applications, limitations and challenges. Computers and Electronics in Agriculture $79 \quad$ (2011) 42-50. x005f_x005fx005f_x005f_x0002_ 2011 Elsevier B. $V$. All rights reserved.

[26] Gali Navehab, A. E. Information Technology Education in a Digital Factory Learning Environment . Information Technology Education in a Digital Factory Learning Environment, Intelligent Automation \& Soft Computing, $\quad$ DOI: 10.1080/10798587.2015.1022346.

[27] Jaiganesh.S, G. V. IOT Agriculture to improve Food and Farming Technology. Proc. IEEE Conference on Emerging Devices and Smart Systems (ICEDSS 2017) 3-4 March 2017.

[28] Aqeel-ur-Rehman a, b. A. A review of wireless sensors and networks' applications in agriculture. Computer Standards \& Interfaces 36 (2014) 263-270. 2011 Elsevier B.V. All rights reserved.

[29] Azhar Hasan, R. B. A Monopole-Coupled RFID Sensor For Pervasive Soill Moisture 
Monitoring.DOI:10.1109/ APS.2013.6711813. IEEE 27 January 2014

[30] Sérgio Francisco Pichorim, N. J. Two Solutions of Soil Moisture Sensing with RFID for Landslide Monitoring. Sensors 2018, 18, 452; doi:10.3390/s18020452.

[31] Diana Rahmawati1, d. K. Perancangan kebun Mini hemat asitr dengan Sistem Mikro Irigasi Fuzzy Otomatis Menggunakan Arduino . Rekayasa Vol. 8, No. 2, Oktober 2015, hlm. 95108.

[32] Fang, J.-A. J.-S.-S.-K.-Y.-H.-T. Toward a higher yield: a wireless sensor network-based temperature monitoring and fan-circulating system for precision cultivation in plant factories. Precision Agric https:// doi.org/10.1007/s11119-018-9565-6.(C)

Springer Science+Business Media, LLC, part of Springer Nature 2018

[33] Hidayat, T. Internet of Things Smart Agriculture on Zig Bee: A Systematic Review. Incom Tech, Jurnal Telekomunikasi dan Komputer, vol. 8, no.1, Juni 2017.

[34] Jun Zhang, G. Y. A Review of Passive RFID Tag Antenna-Based Sensors and Systems for Structural Health Monitoring Applications. Sensors, 2017,17, 265; doi:10.3390 Is17020265. sensors .

[35] Foughali Karima, F. K. Monitoring system using web of things in precision agriculture. ScienceDirect Available online at www.sciencedirect.com Procedia Computer Science 110 (2017) 402-409.

[36] Kienzle, B. S. Sustainable Agricultural Mechanization for Smallholders: What Is It and How Can We Implement It? Agriculture 2017, 7, 50; doi:10.3390/agriculture7060050.

[37] Seyed Hamed Alemohammad, J. K. Global Downscaling of Remotely-Sensed Soil Moisture using Neural Networks. Hydrol. Earth-Syst-Sci..https://doi.org/10.5194/hess2017-680. 8 February 2018.

[38] Mohanraj, K. A.. Field Monitoring and Automation using IOT in Agriculture Domain. Procedia Computer Science 93 ( 2016 ) 931 939 ScienceDirect.

[39] Michailidis, G. K. Educational needs and perceptions of the sustainability of precision agriculture: survey evidence from Greece. Precision Agric DOI 10.1007/s11119-0179537-2. Springer Science+Business Media, LLC 2017.
[40] hha, K. Operational Monitoring System OMS with WSN (Wireless Sensor Network), RFID, GPS \& CCTV in Agriculture. Kadc hha, Orient. J. Comp. Sci. \& Technol., Vol. 9(1), 4145

(2016).

http://dx.doi.org/10.13005/ojcst/901.08 .

[41] Madhuri Sharon, A. K.. Nanotechnology In Agricultural Diseases And Food Safety. Journal of Phytology 2010, 2(4): 83-92.

[42] Ravid, A. G. Applying machine learning on sensor data for irrigation recommendations: revealing the agronomist's tacit knowledge. Springer Science+Business Media New York 2017. Precision Agric. DOI 10.1007/s11119017-9527-4.

[43] Robert Schima, H. M. (n.d.). Technical Note Imagine All the Plants: Evaluation of a LightField Camera for On-Site Crop Growth Monitoring. Remote Sens. 2016, 8, 823; doi:10.3390/rs8100823.

www.mdpi.com/journal/remotesensing.

[44] Sangkil Kim, T. L. An RFID-enabled Inkjetprinted Soil Moisture Sensor on Paper for "Smart" Agricultural Applications. 978-14799-0162-3/14/\$31.00 @2014 IEEE.

[45] T. K. Hamrita, E. C. Development of A "Smart" Wireless Solil Monitoring Sensor Prototype Using RFID Technology. Applied Engineering in Agriculture Vol. 21(1): 139-143 2005 American Society of Agricultural Engineers ISSN 0883-8542.

[46] Xiaolin Jia, Q. F. RFID Technology and Its Applications in Internet of Things (IOT) . 9781-4577-1415-3/12/\$26.00 @2012 IEEE.

[47] Tajudee abiodun, A. Y. An RFID-based Variabel Rate Technology Fertilizer Applicator for Tree Corp. Journal of Applied Science 13 (3): 409-415, 2013/ DOI : 10.3923/jas 2014.409.415.

[48] Tien-Dung Nguyen, T.-P. C.-H.-H. On improving agricultural IoT management. Journal of Information and Telecommunication, 1:3, 208-223, DOI: 10.1080/24751839.2017.1347393.

[49] Yusuf Priyandari, Y. Desain Model Sistem Ketertelusuran Buah-Buahan di Tingkat Petani Menggunakan Teknologi RFID. Desain Model Sistem Ketertelusuran Buah-Buahan di Tingkat Petani Menggunakan Teknologi RFID.

[50] Zhang, C. Z. An RFID-based solution for monitoring sprayer movement in an orchard/vineyard. Precision Agric (2018)- 
19:477-496 https: //doi.org/10.1007/s11119017-9531-8.

[51] Tan, L. Cloud-based Decision Support and Automation for Precision Agriculture in Orchards. IFAC-PapersOnLine 49-16 (2016) 330-335.

[52] Zhao Liqiang, Y. S. A Crop Monitoring System Based on Wireless Sensor Network. Procedia Environmental Sciences 11 (2011) $558-565$.

\section{BiodataPenulis}

Wenny Marthiana, lahir di Palembang, 29 Maret 1968. Sarjana Teknik Mesin dari Universitas Indonesia Jakarta, lulus 1992. Tahun 2000 memperoleh gelar Magister Teknik Mesin pada Jurusan Teknik Mesin Universitas Indonesia, Jakarta. Saat ini Staf pengajar pada Jurusan Teknik Mesin Universitas Bung Hatta Padang sejak tahun 2002- sekarang.

Nizwardi Jalinus, lahir di Palembang, pada 22 Agustus 1952. Saat ini aktif sebagai dosen sekaligus ketua Prodi Pasca Sarjana Program Doktor di Fakultas Teknik jurusan Pendidikan Teknologi Kejuruan Universitas Negeri Padang 
